\title{
OVERVIEW OF ATMOSPHERIC IONIZING RADIATION (AIR) RESEARCH: SST-PRESENT
}

\author{
J.W. Wilson ${ }^{1}$, P. Goldhagen ${ }^{2}$, V. Rafinsson ${ }^{3}$, J. M. Clem ${ }^{4}$, G. De Angelis ${ }^{5,6}$ W. Friedberg ${ }^{7}$ \\ ${ }^{1}$ NASA Langley Research Center, Hampton VA 23681 USA \\ ${ }^{2}$ DOE Environmental Measurements Laboratory, New York NY 10014 USA \\ ${ }^{3}$ University of Iceland, Reykjavik, Iceland \\ ${ }^{4}$ Bartol Research Institute, University of Delaware, Newark DE 19716 USA \\ ${ }^{5}$ Old Dominion University, Norfolk VA 23508 USA \\ 'Istituto Superiore di Sanita', Rome, Italy \\ ${ }^{7}$ Civil Aerospace Medical Institute, FAA, Oklahoma City, OK 73125 USA
}

\begin{abstract}
The Supersonic Transport (SST) program, proposed in 1961, first raised concern for the exposure of pregnant occupants by solar energetic particles (SEP), and neutrons were suspected to have a main role in particle propagation deep into the atmosphere. An eight-year flight program confirmed the role of SEP as a significant hazard and of the neutrons as contributing over half of the galactic cosmic ray (GCR) exposures, with the largest contribution from neutrons above $10 \mathrm{MeV}$. The FAA Advisory Committee on the Radiobiological Aspects of the SST provided operational requirements. The more recent (1990) lowering of recommended exposure limits by the International Commission on Radiological Protection with the classification of aircrew as "radiation workers" renewed interest in GCR background exposures at commercial flight altitudes and stimulated epidemiological studies in Europe, Japan, Canada and the USA. The proposed development of a High Speed Civil Transport (HSCT) required validation of the role of high-energy neutrons, and this resulted in ER-2 flights at solar minimum (June 1997) and studies on effects of aircraft materials on interior exposures. Recent evaluation of health outcomes of DOE nuclear workers resulted in legislation for health compensation in year 2000 and recent European aircrew epidemiological studies of health outcomes bring renewed interest in aircraft radiation exposures. As improved radiation models become available, it is imperative that a corresponding epidemiological program of US aircrew be implemented.
\end{abstract}

\section{INTRODUCTION}

After the discovery of radiation emanating from certain materials, the source of background radiation observed in the atmosphere was thought to have exclusively originated from the ground, however Hess's series of balloon flights from 1911-1913 showed that an additional component originating from the sky was also present in this background. In 1925, Millikan coined this newly discovered radiation as cosmic rays.

The fact that the cosmic rays consisted in part of charged particles was directly demonstrated by coincidence experiments using Geiger-Mueller tubes and resolving individual charged particle tracks within a Wilson cloud chamber. The cloud chamber lead to the discovery of the positron as part of the cosmic rays, followed by the discovery of the charged mesons, and further shed light on the important neutron component of cosmic radiation in the atmosphere (Bethe et al. 1940). Worldwide surveys of cosmic ionization during the years 1931-1932 were made by several groups and Hess of Austria studied time variations associated with solar activity cycle on a mountaintop from 1931-1937. Global radiation levels correlated well with the expected effects of the geomagnetic deflection of cosmic radiation. A worldwide network of stations began to develop leading to observed short-term fluctuations in the global ionization rates simultaneously in both the southern and northern hemispheres 
and was correlated with solar disturbances (Hess and Eugster 1949). Observed large increases in the ionization rates would be attributed to particles coming directly from the solar events (Fig. 1). More modest decreases over a few days, as seen for the July-August 1946 event, were attributed to disturbance of the local interplanetary medium by which approaching cosmic rays were excluded from the local Earth environment (Forbush decrease). It was now clear that extraterrestrial radiation from both the sun and the galaxy were contributing to the atmospheric ionization levels. The next-to-last piece of important evidence from a human exposure perspective was the discovery of heavy ion tracks by Phyllis Frier and coworkers (1948) using nuclear emulsion track detectors in high altitude balloon flight. Although the initial emphasis of this discovery was the ability to sample cosmic matter, attention would turn to the possibility of human exposure by these ions in high-altitude aircraft and future space travel (Armstrong et al. 1949, Schaefer 1950, 1952, 1959, Alkofer and Heinrich 1974).

When the possibility of high-altitude supersonic commercial aviation was first seriously proposed, Foelsche brought to light a number of concerns for the associated atmospheric radiation exposure due to penetrating cosmic rays (CR) from the galaxy (GCR) and the sun (SCR, also referred to as solar particle events, SPE) including the secondary radiations produced in collision with air nuclei (Foelsche 1961, Foelsche and Graul 1962, Foelsche 1965). Subsequently, a detailed study of the atmospheric ionizing-radiation components at high altitudes was conducted from 1965 to 1971 at the NASA Langley Research Center (LaRC) by Foelsche et al. $(1969,1974)$. Prior to that study the role of atmospheric neutrons in radiation exposure was generally regarded as negligible (ICRP 1966). The LaRC studies revealed the neutron radiation to be the major contributor to commercial aircraft GCR exposure. Still the exposure levels were comfortably below allowable exposure limits for the block hours typical of airline crews of that time except during a possible solar particle event (less than 500 block hours were typical of the 1960's although regulations allowed up to 1000 hours). As a result, the US

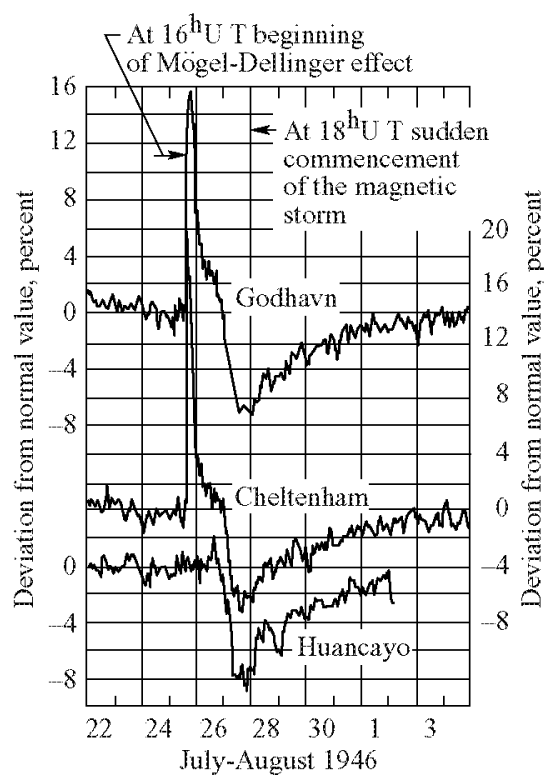

Fig. 1 Ground level ion chamber observations of solar particle events of 1946 and 1949. (From Foelsche et al. 1974) Federal Aviation Agency (FAA)

Advisory Committee on the Radiobiological Aspects of the SST issued recommendations that crew members will have to be informed of their exposure levels, maximum exposures on any flight be limited to $5 \mathrm{mSv}$, development of airborne radiation monitors, development of a satellite monitoring system, and development of a solar event forecasting service (FAA 1975, see also Foelsche et al. 1974).

Several factors have changed since those early studies: (a) the highly ionizing components are found to be more biologically damaging than previously assumed and the associated quality factors for fatal cancer have been increased (ICRU 1986, ICRP 1991); (b) recent studies on developmental injury in mice embryo indicate larger quality factors are required for protection in prenatal exposures (Jiang et al. 1994); (c) recent epidemiological studies (especially the data on solid tumors) and more recent A-bomb survivor dosimetry have resulted in higher radiation risk coefficients for $\gamma$ rays (UNSCEAR 1988, BEIR V 1990, ICRP 1991) resulting in lower proposed permissible limits (ICRP 1991, NCRP 1993); (d) "an urgent need is recognized for better estimates of the risk of cancer from low levels of radiation" (anon. 1993); (e) subsequent to deregulation of the airline industry, flight crews are logging greatly increased flight hours (Bramlett 1985, Wilson and Townsend 1988, Friedberg et al. 1989, Barish 1990); (f) a new class of long haul commercial aircraft is being developed on which personnel for two crew shifts will be simultaneously aboard a single flight leading to increased exposures for a fixed number of flight duty hours (Lebuser 1993); (g) US airline crew members are now classified as radiation workers (McMeekin 1990, ICRP 1991); (h) NASA is developing technology for a High Speed Civil Transport (HSCT) to begin service in the twenty-first century; and $(\mathrm{g})$ there are plans to introduce a revolutionary commercial transport (Mach 0.98 Sonic 
Cruiser) with operating altitudes from 45,000$51,000 \mathrm{ft}$ (Boeing 2002). In recognition of the potential impact of several of these factors on present day crew exposures, the Commission of the European Communities organized a Workshop on Radiation Exposure of Civil Aircrew (Reitz et al. 1993). The workshop conclusions (mainly for subsonic exposures) are that the environment is not adequately known for reliable estimates of dose equivalent resulting mainly from uncertainty in the neutron spectra at high energies and a re-evaluation of the heavy ion component should be made. More recently the International Civil Aviation Organization (ICAO) has recommended that "All airplanes intended to be operated above $15000 \mathrm{~m}$ (49000 ft) shall carry equipment to measure and indicate continuously the dose rate of total cosmic radiation being received (i.e., the total of ionizing and neutron radiation of galactic and solar origin) and the cumulative dose on each flight. The display unit of the equipment shall be readily visible to a flight crew member" (ICAO 1995). More recently Japanese flight crews have requested from their government, health benefits on the basis that their exposures are "far greater than the exposure of the average nuclear power plant worker" (Fiorino 1996). Added emphasis comes from epidemiological studies of health outcomes among Department of Energy contractors (NEC 2000) leading to the Energy Employees Occupational Illness Compensation Program Act of 2000. Finally, it is clear that the development of advanced high-altitude commercial aircraft (such as the HSCT) requires some attention to the past concerns of high-altitude flight but in terms of current day knowledge and uncertainty in that knowledge (Wilson et al. 1995). In a prior report, we reviewed the status of knowledge of human occupational exposures and related uncertainties in health risks (Wilson 2000). It was clear that exposures among aircrew were generally higher than other terrestrial occupationally exposed groups and the aircrew risk uncertainties were high since a large fraction of the exposure is from highLET radiations.

In this paper we will review key historical developments in our understanding of atmospheric ionizing radiation and its impact on commercial operations. Although such a review cannot be made without reference to work outside the US, we leave the thorough review of European research to O'Sullivan et al. (2003) in this issue. A brief overview of ongoing research in the US is given with special emphasis on future requirements.

\section{PAST AIR STUDIES}

The primary concern for commercial aircraft radiation exposures began with the Supersonic Transport with a projected high operating altitude $(20-\mathrm{km})$ for service on transoceanic flights. Foelsche raised concern on vulnerability on the high-latitude routes from the US eastern seaboard to Europe where extraterrestrial particles easily penetrate the geomagnetic field and intense solar

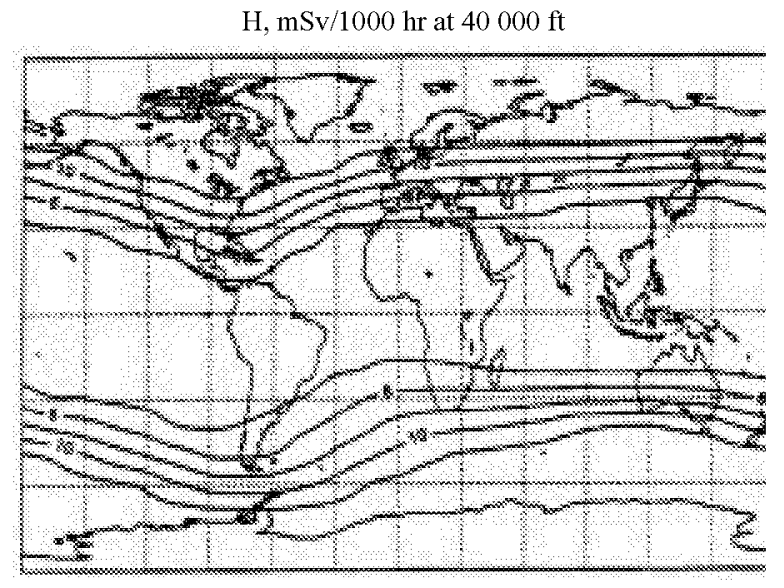

$\mathrm{H}, \mathrm{mSv} / 1000 \mathrm{hr}$ at $50000 \mathrm{ft}$

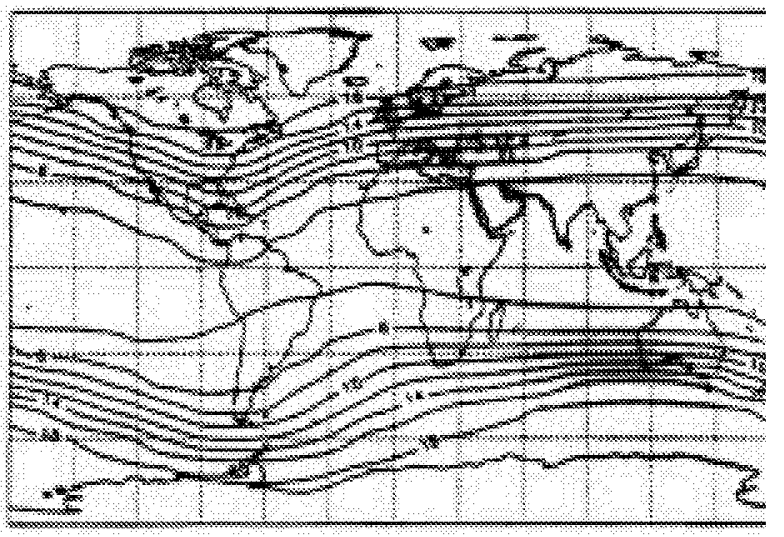

Fig. 3 Background exposure levels (AIR model) in atmosphere at solar minimum (1965). 
particle events could induce unacceptable exposures on a single high-altitude flight. It was assumed that the neutrons produced in nuclear reactions with atmospheric nuclei would play an important role in carrying the dose equivalent deeper into the atmosphere and potentially contribute to background exposures. A measurement program was initiated by NASA at the Langley Research Center (LaRC) to resolve these issues in July 1964.

The LaRC commissioned over 300 flights over most of the duration of solar cycle 20 on high-altitude aircraft and balloons to study both background radiation levels over the solar cycle and to make measurements during a solar particle event. The Langley flight package consisted of a 1-10 MeV neutron spectrometer, tissue equivalent ion chamber, and nuclear emulsion for nuclear reaction rates in tissue. Monte Carlo calculations (Wilson et al. 1970, Lambiotte et al. 1971) for incident GCR protons were used to extend the neutron spectrum to high energies (Fig. 2). Also shown in Fig. 2 are the contributions to dose and dose equivalent from neutrons on individual energy decades. The measured data was integrated into a parametric Atmospheric Ionizing Radiation (AIR) model scaled with Deep River neutron monitor count rate and geomagnetic vertical cutoff rigidity (Wilson et al. 1991). The solar minimum global exposures are shown in Fig. 3 at two altitudes. Over half of the neutron dose is from neutrons above $10 \mathrm{MeV}$ and an accurate knowledge of the high-energy neutron quality factors is critical to evaluation of dose equivalent. About half of the dose equivalent is from neutrons as shown in Fig. 4. Additional high-LET components come from the nuclear reactions caused by the charged hadrons so that well over half of the exposures in commercial operations are from high-LET events which leaves large uncertainties in the associated health risks (Wilson 2000, Cucinotta et al. 2001) even if the radiation levels are accurately known.

The only solar particle events of interest are those capable of ground level observations with ion chambers (Fig. 1) or neutron monitors. The rates of occurrence of such events (Shea and Smart 1993) are shown in Fig. 5. The ground level events vary greatly in intensity and only the most intense events are important to high-altitude aircraft protection. The largest ground level event yet observed occurred on Feb. 23, 1956 in which neutron count rates rose to 3,600 percent above background. Two of the afore mentioned over 300 flights were made out of Fairbanks, Alaska during the event of March 30-31, 1969 with results shown in Fig. 6. If the ground level increase for the March 1969 event is used to scale other historical ground level events, we conclude that high-levels ( $1 \mathrm{cSv}$ or more) of radiation exposure were present at aircraft altitudes in the past. The uncertainties in the proton spectra for the Feb. 1956 event are large but upper and lower bounds estimated by Foelsche result in dose equivalent rates from Monte Carlo calculations (Foelsche et al. 1969, Wilson et al. 1970, Armstrong et al. 1969) in qualitative agreement with those derived from simply scaling the March 1969 data. The Monte Carlo results are shown in Fig. 7 as
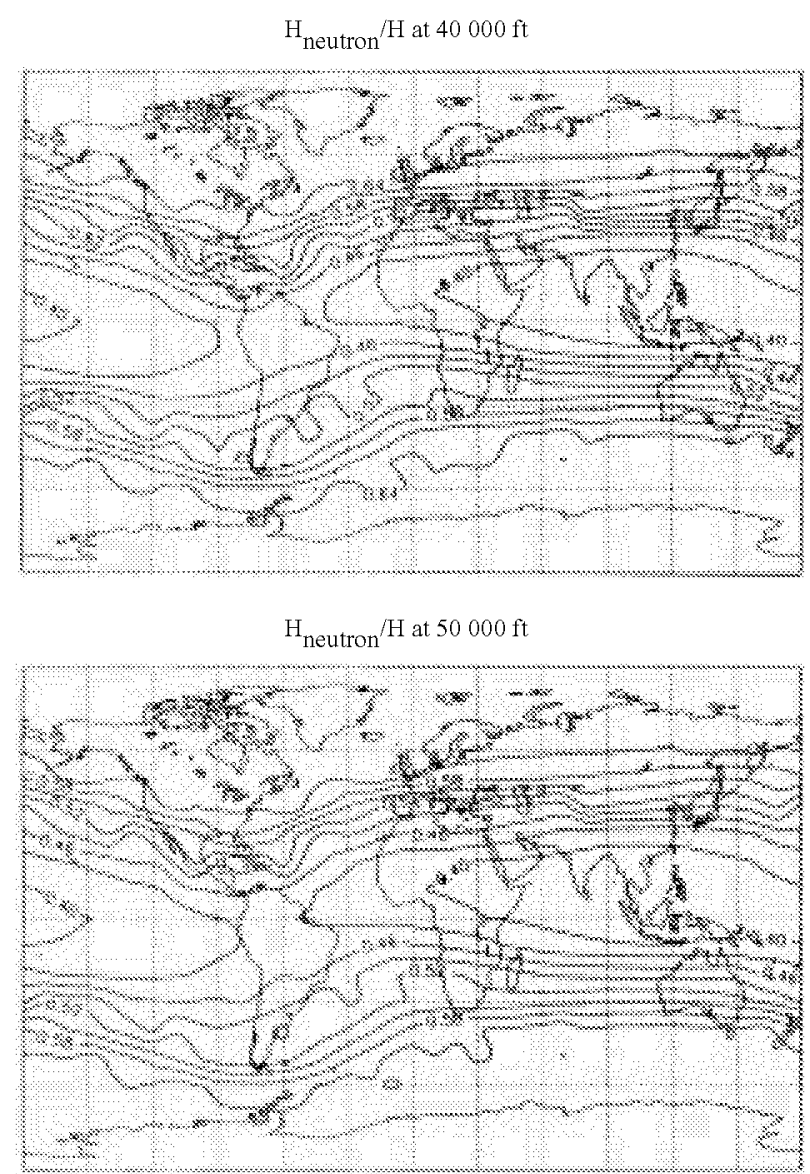

Fig. 4 Fraction of dose equivalent (AIR model) due to neutrons at solar minimum (1965).

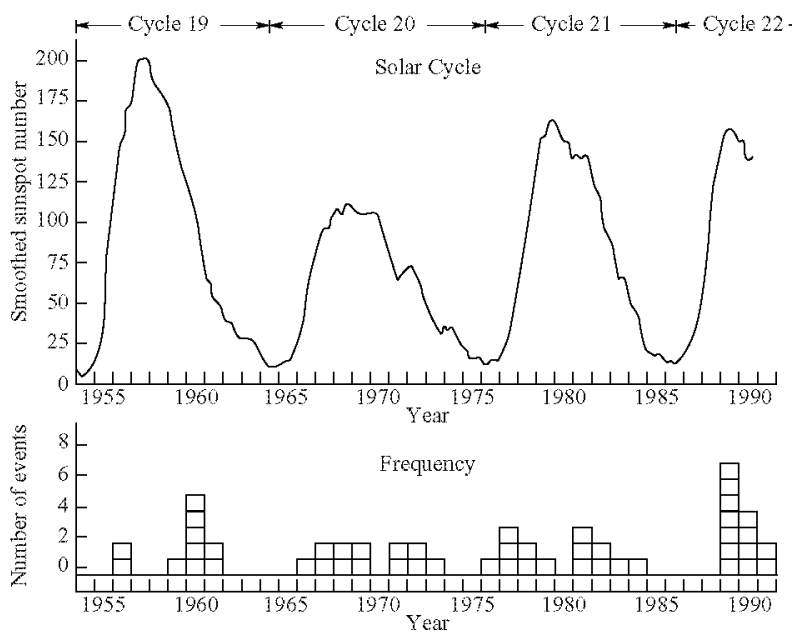

Fig. 5 Temporal distribution of ground level solar particle events for the past 40 years. (Shea and Smart 
calculated by the Langley code (Wilson et al. 1970) and Amstrong et al. (1969) at Oak Ridge National Laboratory using the High Energy Transport Code (HETC). The results in the figure use the maximum surface dose equivalent conversion factors for a $30-\mathrm{cm}$ tissue slab geometry. Dose equivalent averaged over the $30-\mathrm{cm}$ slab is approximately a factor of 2-3 lower for solar particle events (Foelsche et al. 1974). It was clear from these results that exposures to crew and passengers on high-latitude routes of the SST flying at $58 \mathrm{~g} / \mathrm{cm}^{2}$ would be unacceptable unless descent to subsonic altitudes was possible to minimize exposures during such a large event. The importance of such events is limited to the Polar Regions.

The main concern of these early studies was the potential prenatal injury in high-altitude flight especially during such a possible large solar event since crew and passengers included women of childbearing age. It is seen in Fig. 3 that flights from the US northeast to Europe fly along the edge of the polar region and are subject to solar particle event exposures (Wilson et al. 1995). An advisory committee to the Federal Aviation Administration (FAA 1975) recommended that a satellite earlywarning/monitoring system be established, active onboard monitoring devices be included in the aircraft design, and that operational procedures be developed to insure that exposures on a given flight be limited to $5 \mathrm{mSv}$. Although many ground level events occur, only a few have been of such intensity as to be of concern to near term high-altitude air traffic. The second largest ground level event observed over the last 60 years is the event on September
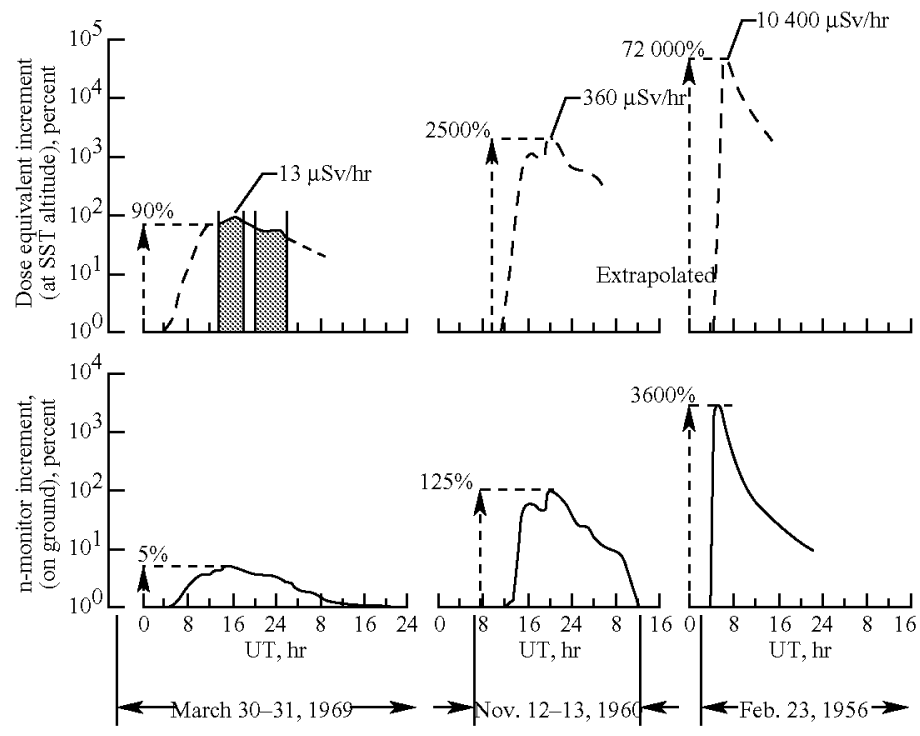

Fig. 6. Energetic solar events measured on the ground and at SST altitude.

29, 1989. This event was similar to the February 23, 1956 event in its time course and spectral content but of an order of magnitude lower intensity (on the order of $1 \mathrm{mSv} / \mathrm{hr}$ ) and of less concern to supersonic operations. Since the February 23, 1956 event is the only outstanding event, it leaves a heavy operational overhead requirement for such an unlikely occurrence. Yet, it is likely such an event will occur again and perhaps an even larger event. It is fortunate that high-altitude aircraft requirements are largely met by the space program and weather service requirements providing potential cost sharing (Wilson 1981).

\section{RECENT AIR STUDIES}

Many factors relative to aircraft exposures have changed over the last decade as recounted in the introduction. There are continued studies of a possible hypersonic air transport, which will bring a host of new issues as reviewed elsewhere (Wilson 2000). Two key events had an important impact on requirements for atmospheric ionizing radiation research over the last decade: the ICRP (1991) included aircrew among the defined occupationally exposed and NASA initiated a technology assessment for a possible secondgeneration supersonic transport (High Speed Civil Transport, ISCT).

Although a consistent data set over much of the Earth's surface and most of solar cycle 20 has been measured by the LaRC SST program, many of the individual components were not resolved due to instrument limitations at the time of measurement (circa 1964) and the major portion of the neutron spectrum depended on theoretical calculations for proton interactions with the atmosphere (Foelsche et al. 1974). Hewitt et at. (1978) measured the neutron spectrum using a

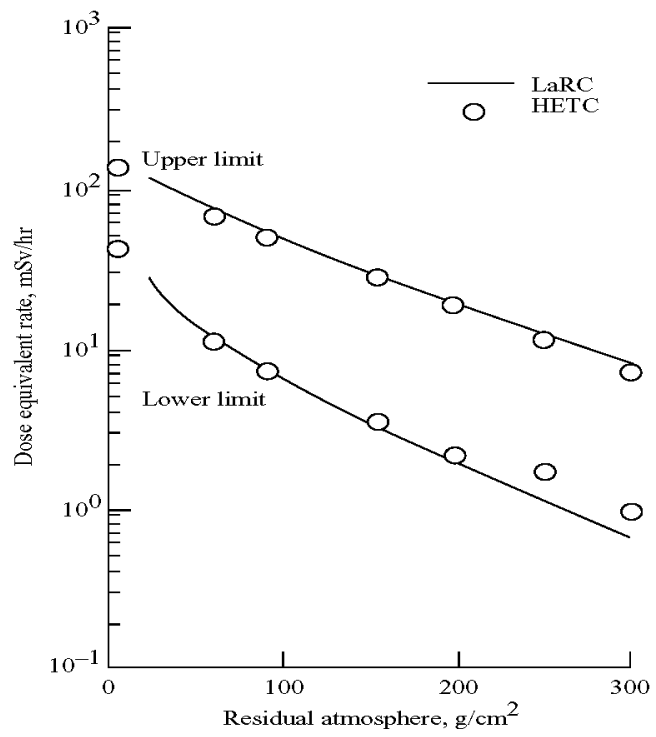

Fig. 7 Calculated upper and lower limits for dose equivalent rate at high latitude for the Feh. 23. 1956 event 
Bonner sphere set up at subsonic altitudes and analyzed the data assuming a simple power spectrum and confirmed the importance of the high-energy neutrons but left the exact nature of the spectrum uncertain due to limitations of the analysis methods. Ferenc Hajnal of the DOE Environmental Measurements Laboratory developed new analysis techniques for unfolding Bonner sphere neutron spectral data and found important structural features in Hewitt's data near $100 \mathrm{MeV}$ (see Fig. 8) that have important implications for aircraft exposures (Hajnal and Wilson 1991, 1992). A quick survey of published atmospheric neutron spectra shows considerable uncertainty in our knowledge and the impact of these uncertainties are analyzed elsewhere (Wilson et al. 1995, Wilson 2000). The status of knowledge of atmospheric ionizing radiation was reviewed by the NCRP (1996) providing a basis for continued studies in support of the HSCT technology assessment activity.

Further studies were started at the Langley Research Center. An instrument package was developed in accordance with the NCRP recommendations through an international guest investigator collaborative project, thereby ensuring the availability of the numerous instruments required measuring the many components of the radiation spectra and providing a calibration platform for dosimetry. Selection criteria included: (a) the instruments had to fit within the cargo bay areas of the ER-2 airplane and be able to function in that environment, (b) the instruments had to be provided at no cost to meet budget constraints, (c) each instrument must have a principal investigator with independent resources to conduct data analysis, and (d) the instrument array must be able to measure all significant radiation components for

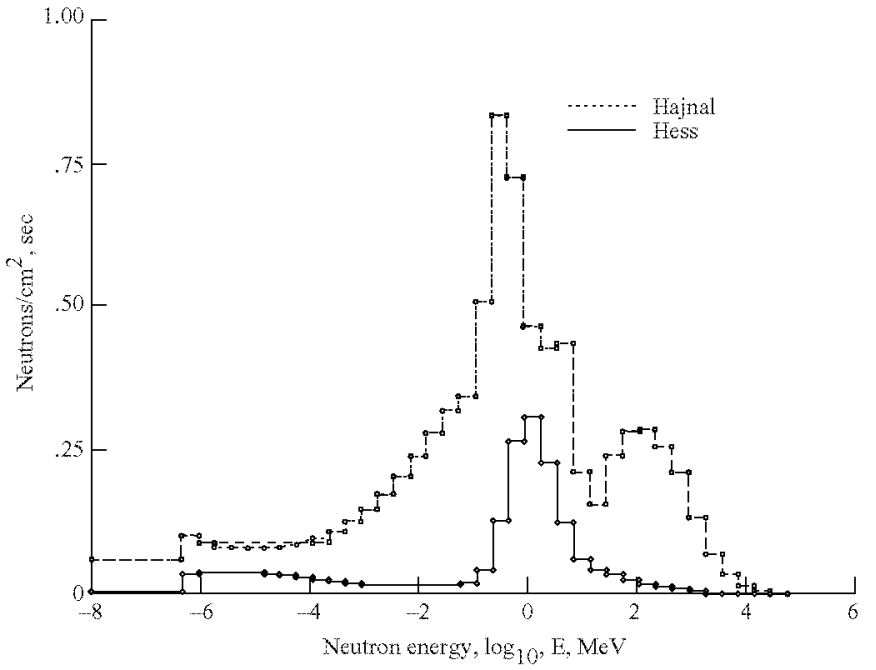

Fig. 8 Hajnal unfolded neutron spectrum from Hewitt data measured at $17.46^{\circ} \mathrm{N}$ at $23.5 \mathrm{~km}$ compared to Hess et al. (1961) spectrum. which the NCRP (1996) had established minimal requirements. Also, the flight package had to be operational and the first flight to occur before or near the maximum in the galactic cosmic ray intensity (spring/summer 1997) and continued through the next cosmic ray minimum.

The flight package was a collaboration of fourteen institutions in five countries and consisted of eighteen instruments able to separate the various physical components and tested various dosimeters (Goldhagen et al. 2000). The flight plan was established using the first AIR model (Tai et al. 1998) and concentrated on north/south surveys with an altitude profile at the northern extremity. The first flight series in June 1997 met with considerable success with the loss of only one instrument in the data flow. The flight program ended with the decision that technology was not ready to develop a competitive high-speed civil transport but the data analysis continues to this day including corrections for the ER-2 flight platform structure. Preliminary neutron spectra (Goldhagen et al. 2002) are shown in Fig. 9 and tend to confirm the results of Hajnal's analysis (Fig. 8). Note that the neutron spectra of the northern and southern fight extremes, where the geomagnetic cutoffs differ by more than an order of magnitude, are similar in spectral content with different magnitude. This corresponds well with the more limited results of Foelsche et al. (1974), who likewise concluded that the spectrum has negligible differences in the upper atmosphere as a function of altitude and latitude.

A preliminary comparison of the first $A I R$ model with the high-pressure argon ion chamber is given in Fig. 10. This was approximately a six and

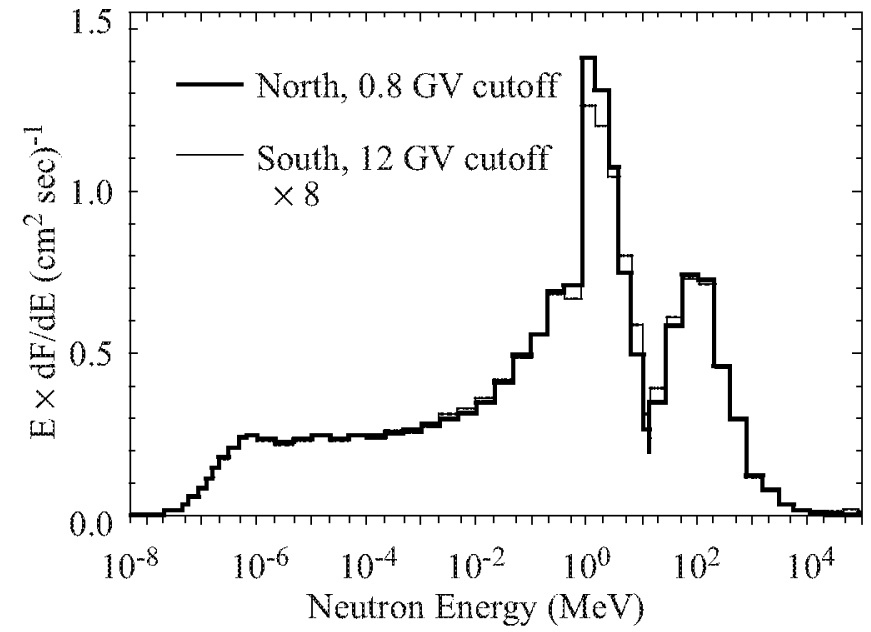

Fig. 9. Cosmic-ray neutron spectra measured at the northern end $\left(54^{\circ} \mathrm{N}, 117^{\circ} \mathrm{W}, 0.8 \mathrm{GV}\right.$ cutoff, $56 \mathrm{~g} \mathrm{~cm}^{-2}$ atmospheric depth) and at the south end $\left(19^{\circ} \mathrm{N}, 127^{\circ} \mathrm{W}, 12\right.$ GV cutoff; $54 \mathrm{~g} \mathrm{~cm}^{-2}$ atmospheric depth). The south spectrum is multiplied by 8 . 
one-half hour flight starting June 13,1997 at 15:52 from NASA Ames Research Center on a prescribed sequence of northern, western, and southern headings. This was the second northern flight and the aim was to approximately repeat the radiation measurements as a function of geomagnetic latitude to as far north as possible with altitude excursions along a constant-radiation, geomagnetic latitude line near Edmonton, Canada. During the westward portion of the flight, an altitude excursion was made as an altitude survey as evident in the figure. The AIR model using the recorded flight trajectory is shown in the figure for comparison with the measured flight data.

A preliminary summary of European activity is given by McAulay et al. (1996). Further study of the atmospheric neutron spectrum lead by H. Schraube of GSF in Neuherberg has been funded by the Directorate General XII. The experimental component consists of a Bonner sphere spectrometer with a ${ }^{3} \mathrm{He}$ proportional counter (Schraube et al. 1998) on a mountaintop (Zugspitze). The theory portion of the study uses the FLUKA code, currently maintained at CERN, and the known cosmic rays incident on the atmosphere (the multiple charged ions are assumed to be dissociated into nucleonic constituents (Roesler et al. 1998). It is interesting to note that the structure expected from the analysis of Hajnal at $100 \mathrm{MeV}$

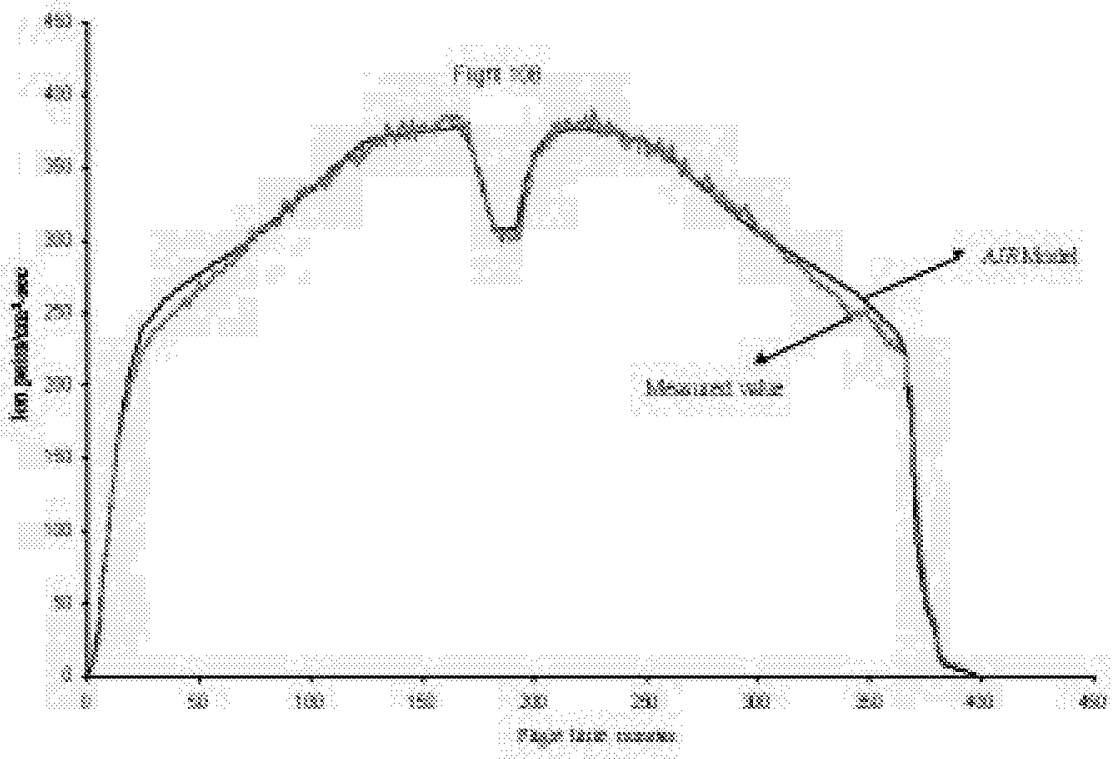

Fig. 10 Predicted and measured value of Air Ionization Rate as function of time for Flight 97-108, June 13, 1997.

(Fig. 8) appears in both the measurements and the FLUKA calculation (see Fig. 11). Note that this feature was absent from the LUIN code available at the time of the study. LUIN then depended on the Hess et al. (1961) spectrum for guidance as to the shape of the neutron spectrum at low energies. Thus the LUN code is not a basic physics model in that it contains information outside the basic LUN transport model (O'Brien and Friedberg 1994). Schraube et al. (1998) showed that the neutron ambient dose equivalent is about a factor of two larger than that estimated by LUIN; the added contributions are from high-energy neutron interactions with tissue nuclei resulting in an array of high-LET reaction products at each collision event. LUIN99 and LUIN2000 (O'Brien et al., 2003) address this issue by using Rösler et al. (1998) neutronspectrum results. Very little biological data exist on such radiations (Wilson et al. 1990, Wilson 2000, Cucinotta et al. $2001)$.

It was determined by Foelsche et al. (1974) using simultaneous flight measurements with a research aircraft and a balloon that local neutron production in materials of a small research aircraft added 10 percent to the measured neutron field. Later measurements by Wilson et al. (1994) onboard commercial subsonic transports

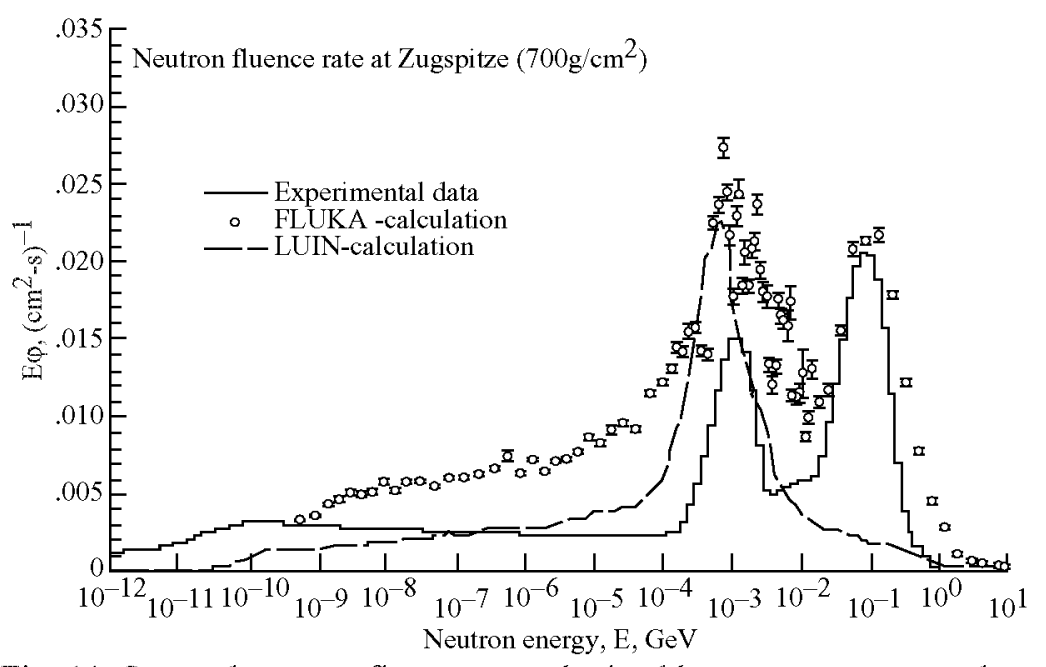

Fig. 11 Spectral neutron fuence rate obtained by measurements and calculations on top of Zugspitze (by permission of Schraube et al. 1998). 
found that the radiation levels varied by up to 30 percent within the aircraft cabin space. These results give incentive to evaluation of aircraft materials as a means to providing limited control of the interior environment. Evaluation of aircraft design alternatives requires a physics-based AIR model for which the transmission properties of aircraft materials can be folded into the design process.

\section{POLICY \& EPIDEMIOLOGY}

Aside from the question of more restrictive regulatory requirements resulting in a FAA advisory (McMeekin 1990) there is increased concern for potential health outcomes among the crew in commercial aviation. The health outcomes are undoubtably related to environmental factors including radiation. Studies continue to expand giving greater statistical resolving power (De Angelis et al. 200la). Although as a group the health risks of this select group of individuals are low (healthy worker effect, for the specific case of aircrew members, see De Angelis et al, 2001b), Band (1990) found increased risks of several types of cancer among Canadian commercial pilots. Further concern for some of the most sensitive occupants of commercial aircraft, the US National Institute for Occupational Safety and Health continues a study of early pregnancy outcomes among commercial flight attendants (Grajewski et al. 1994, Whelan 2002).

Table 1. Cancer Sites with significant positive association for civilian airline flight personnel crewmembers. Confidence limits are 90 or 95 percent depending on study.

\begin{tabular}{|c|c|c|c|c|c|c|}
\hline Cancer Site & Sex & Job & Type & $\begin{array}{l}\text { Cont } \\
\text { Limi }\end{array}$ & dence & Source \\
\hline All Sites* & $\mathrm{M}$ & $\mathrm{CA}$ & SIR & 1.3 & 2.2 & Haldorsen et al. (2001) \\
\hline Bone & $\mathrm{F}$ & $\mathrm{CA}$ & SIR & 1.8 & 54.4 & Pukkala et al. (1995) \\
\hline Brain & $\mathrm{M}$ & $\mathrm{P}$ & SIR & 1.2 & 7.9 & Band et al. $(1990)$ \\
\hline Brain & $\bar{M}$ & $\mathrm{P}$ & SMR & 1.4 & 9.5 & Band et al. (1990) \\
\hline Breast & $\mathrm{F}$ & $\mathrm{CA}$ & SIR & 1.2 & 2.2 & Pukkala et al. (1995) \\
\hline Breast & $\mathrm{F}$ & $\mathrm{CA}$ & SIR & 1.0 & 4.3 & Wartenberg et al. $(1998,1999)$ \\
\hline Breast & $\mathrm{F}$ & $\mathrm{CA}$ & SIR & 1.09 & 1.83 & Reynolds et al. (2002) \\
\hline Esophagus & $\mathrm{M}$ & $\mathrm{CA}$ & SIR & 2.7 & 11.4 & Haldorsen et al. (2001) \\
\hline Hodgkin Lymphoma & $\mathrm{M}$ & $\mathrm{P}$ & SIR & 1.2 & 11.7 & Band et al. (1990) \\
\hline Kidney and Pelvis & $\mathrm{M}+\mathrm{F}$ & $\mathrm{P}$ & PMR & 1.18 & 3.06 & Nicholas et al. (1998) \\
\hline Leukemia - AML & $\mathrm{M}$ & $\mathrm{P}$ & SIR & 2.1 & 9.3 & Band et al. (1996) \\
\hline Leukemia-Myeloid & $\mathrm{M}$ & $\mathrm{P}$ & SIR & 1.4 & 5.5 & Band et al. (1996) \\
\hline Liver* & $\mathrm{M}$ & $\mathrm{CA}$ & SIR & 1.3 & 39.2 & Haldorsen et al. (2001) \\
\hline Prostate & $\mathrm{M}$ & $\mathrm{P}$ & SIR & 1.4 & 2.5 & Band et al. (1996) \\
\hline Rectum & $\mathrm{M}$ & $\mathrm{P}$ & SMR & 1.2 & 11.2 & Band et al. (1990) \\
\hline Skin-Melanoma & $\mathrm{M}$ & $\mathrm{P}$ & SMR & 1.5 & 6.3 & Irvine \& Davies (1999) \\
\hline Skin-Melanoma & $\mathrm{M}$ & $\mathrm{PE}$ & SIR & 1.1 & 2.7 & Haldorsen et al. (2000) \\
\hline Skin-Melanoma & $\mathrm{M}$ & $\mathrm{P}$ & SIR & 5.0 & 36.5 & Rafusson et al. (2000) \\
\hline Skin-Melanoma & $\mathrm{M}$ & $\mathrm{CA}$ & SIR & 1.1 & 6.4 & Haldorsen et al. (2001) \\
\hline Skin-Melanoma & $\mathrm{M}$ & $\mathrm{P}$ & SIR & 2.85 & 4.23 & Nicholas et al. (2001) \\
\hline Skin-Melanoma & $\mathrm{F}$ & $\mathrm{CA}$ & SIR & 1.2 & 6.7 & Rafnsson et al. (2001) \\
\hline Skin-Melanoma & $\mathrm{M}$ & $\mathrm{P}$ & SIR & 1.27 & 4.54 & Hammar et al. (2002) \\
\hline Skin--Melanoma & $\mathrm{F}$ & $\mathrm{CA}$ & SIR & 1.28 & 4.38 & Reynolds et al. (2002) \\
\hline Skin-Other Cancers & $\mathrm{M}$ & $\mathrm{P}$ & SIR & 1.1 & 2.2 & Band et al. $(1990)$ \\
\hline Skin-Other Cancers & $M$ & PE (jets) & SIR & 2.1 & 4.2 & Gundestrup \& Storm (1999) \\
\hline Skin -Other Cancers & $\mathrm{M}$ & $\mathrm{P}$ & SIR & 1.3 & 4.0 & Haldorsen et al. $(2000)$ \\
\hline Skin-Other Cancers* & $\mathrm{M}$ & $\mathrm{CA}$ & SIR & 4.5 & 18.8 & Haldorsen et al. (2001) \\
\hline Prostate\# & M & $\mathrm{P}$ & SIR & 1.19 & 2.29 & Ballard et al. (2000) \\
\hline Skin-Melanomatt & $M$ & $P$ & SMR & 1.02 & 3.82 & Ballard et al. (2000) \\
\hline
\end{tabular}

* cancer outcome possibly related to lifestyle only; \# results from meta-analysis of previous studies, then adjusted for socio-economical status; $\mathrm{AML}=$ Acute Myeloid Leukemia; $\mathrm{CA}=$ Cabin Attendants; $\mathrm{P}=$ Pilots only; $\mathrm{PE}=$ Pilots and flight Engineers; PMR = Proportional Mortality Ratio;

SIR $=$ Standardized Incidence Ratio; SMR = Standardized Mortality Ratio 
Although not a study of commercial aircrew, the report of the National Economic Council (NEC) Panel on Occupational Hazards Associated with Nuclear Weapons Production (NEC 2000) has important implications for commercial aviation. The US President requested the NEC to assess "whether there is evidence of occupational illness in current and former contract workers at the US Department of Energy (DOE) from exposures to occupational hazards unique to nuclear weapons production and evaluate the strength of that evidence." The NEC Panel (Task Group 1) found only modest average annual exposures of the DOE contractor workforce, 1.5 to $2 \mathrm{mSv}$ to 1960 , a slow decline from $1.5 \mathrm{mSv}$ to $1 \mathrm{mSv}$ in 1978 through 1988 , followed to a rapid decline to a few tenths of a mSv past 1990 (compared to an estimated anmual airerew exposure (e.g., Chicago-to-NY) of $2.72 \mathrm{mSv}$, Friedberg et al, 2002). Mortality studies among the DOE contractors showed a healthy worker effect but increased standard mortality and incident ratios (SMRs, SIRs) with 90-95 percent confidence intervals above unity (statistically significant) for cancer of the thyroid, breast, pharynx, esophagus, stomach, small intestine, pancreas, bile ducts, gall bladder, and liver as well as leukemia, multiple myeloma, and lymphomas (except Hodgkin's) as identifiable work related illnesses as concluded by the panel. A compensation program for this entire list of illnesses was set up with some limitations related to possible causality. Furthermore, several cancer sites showed positive correlations with radiation exposures while other cancer sites were assumed to be related to other environmental factors. As a result, the NEC recommended legislation for worker compensation for this restricted list of illnesses which were found with statically significant elevated SMRs and SIRs, leading to the Energy Employees Occupational Illness Compensation Program Act of 2000 passed by the US Congress and signed into law.

A few studies of populations in high-altitude cities have concluded an inverse effect with radiation exposure although Weinberg et al. (1987) argues that oxygen effects may be the source of decreased adverse health risks at high altitudes. More recently studies of US Air Force pilots showed statistically significant elevated risks of cancer in genitals, testis, and urinary systems (Grayson and Lyons 1996). A recent study of mortality among US commercial pilots and navigators found statistically significant elevations of kidney and pelvic cancers (Nicholas et al. 1998). Many European epidemiological studies on health outcomes of aircrew have been in progress for several years (see e.g. Rafusson et al. 2000, 2001, Ballard et al. 2002, and for reviews Ballard et al. 2000, De Angelis et al. $2001 \mathrm{a}, 2001 \mathrm{~b}$ ) and provide additional concern for the need for further studies in the US. It is well established that elevated standard mortality and incidence ratios with 90 to 95 percent confidence intervals above unity is observed among European aircrew as shown in Table 1 along with limited US studies. Even so, one might argue that the SMR and SIR depend on the control group and there are even regional differences as observed in the DOE contractor studies (NEC 2000) and the data still rests on relatively few occurrences in many cases (Friedberg et al. 2002). Still, establishment of policy and science are different issues and the data in Table 1 meets the selection criteria of the NEC panel for compensation (NEC 2000). It is anticipated that US crews who fly generally closer to the magnetic pole than European crews will have both different radiation exposure patterns and distribution of cancers with elevated SMRs. It appears the situation justifies that US aircrews are probably due illness compensatory legislation but insufficient data exists on which to write such legislation. It is imperative that US aircrew epidemiological studies are expanded to correct the current lack of data on cancer incidence and mortality among US aircrew in preparation of required legislation. This impetus follows since, "it is clear that there are health risks associated with a career of flying."

(Friedberg et al. 2002)

\section{CONTINUING US ACTIVITY}

Three issues continue to be addressed within the US: development of the basic $A I R$ model including experimental validation, testing of potential aircraft material transmission properties, and epidemiological studies. The extent of the ongoing activity will be briefly reviewed in this section.

The continued analysis of the ER-2 flight data has concentrated on establishing corrections to the neutron spectrum due to packaging into the flight racks and the surrounding aircraft structure (Goldhagen et al. 2003). This will be followed by analysis of the other instruments used on the flights including the high-pressure ion chamber,

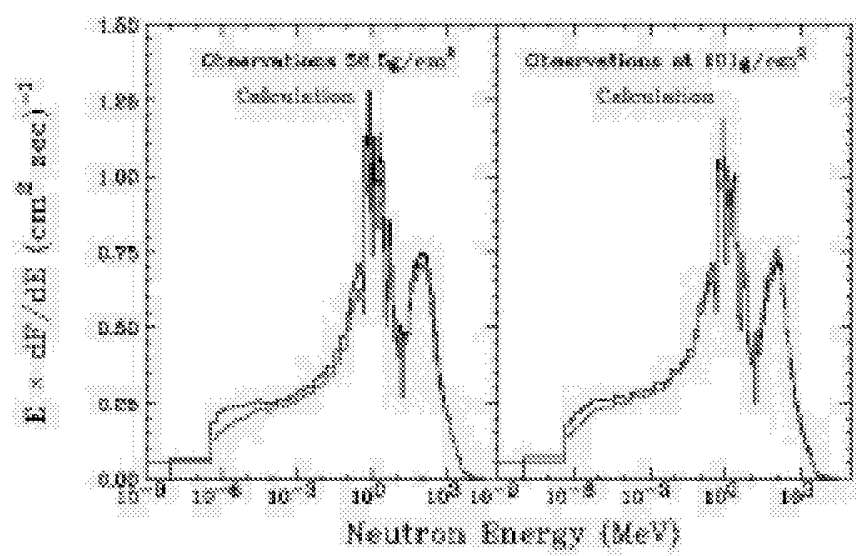

Fig. 12 Comparison of the augmented FLUKA evaluated neutron spectra at the northern extreme of June 1997 ER-2 flight measurements. 
the various scintillators, and particle telescopes. Collaboration with the Bartol Research Institute at the University of Delaware and their unique augmentation of FLUKA to include collisional source terms for multiple charged ions is being evaluated for use in deriving a new physics-based AIR model (Clem et al. 2003). Preliminary comparisons of the altitude survey at the northern extreme of the ER-2 flight shown in Fig. 12 are encouraging. The new AIR model will include a dynamic geomagnetic transmission model for years 1945 to 2020 including geomagnetic storm effects (De Angelis et al. 2003). The fundamental model will be for the particle fields allowing introduction of aircraft geometry and human geometry for final exposure evaluation. One use of the model will be to evaluate single event effects on avionics in future aircraft design. With the historic variation of the geomagnetic transmission factors, the model will enable exposure assessment in retrospective health outcome studies.

The transmission properties of materials in such a complicated environment are poorly understood. The effects of the surrounding aircraft materials and payload on the exposures within the cabin space and on the flight deck are largely unknown. As a result we have designed a flight experiment for the ER-2 aircraft for evaluation of material effects on the local radiation environment. The experiment uses cross-calibrated TEPCs to measure effects on the lineal energy spectra as a function of material type. One rack of the basic apparatus is shown in Fig, 13. There are two such racks that fill the two well-isolated superpod tailcones mounted on the midwings of the ER-2. The measured change in lineal energy spectral content as a function of shield material will give us a degree of measure of the change in the physical fields within the shielded region to evaluate computational shielding models. Fundamental to this usage is an improved understanding of the TEPC response in such mixed radiation fields (Shinn et al. 2001).

The NIOSH/FAA Study of Reproductive Disorders in Female Flight Attendants remains as the only US led epidemiological effort of which we are aware. The study is in three parts: data on reproductive outcomes by questionnaire, ovulation function study using hormone testing, and an environmental assessment of the cabin space (Whelan 2002). Primary school teachers of the same age distribution are being used as a control group for the study.

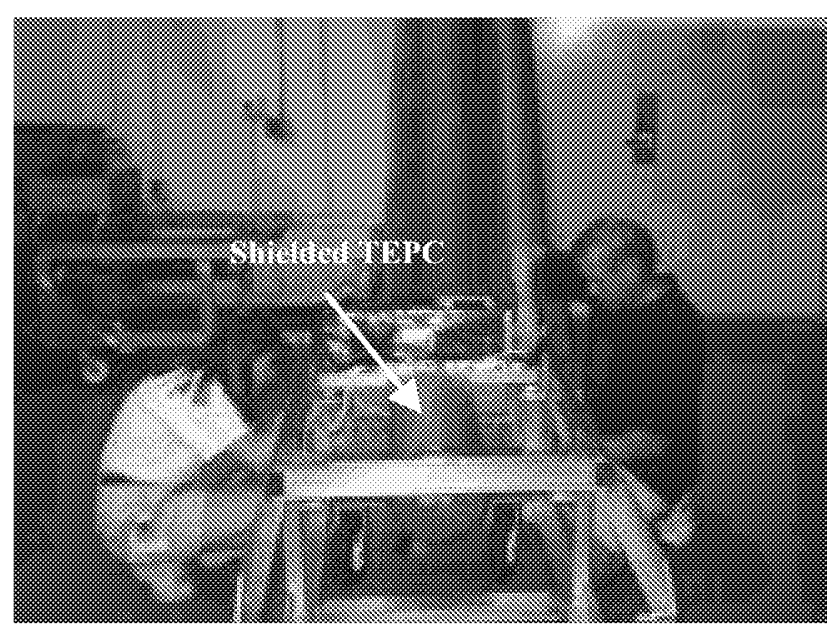

Fig. 13 Aircraft shield materials experiment rack being prepared for ER-2 flight.

\section{CONCLUDING REMARKS}

SST related studies of atmospheric ionizing radiation quantified the exposure fields, established neutrons as the dominant component of radiation health hazard, and identified solar particle event exposures of pregnant occupants as a major health issue. Even then it was recognized that background exposures of commercial aircrew placed them among the most highly exposed occupational groups. As cancer risk coefficients were revised to greater values and corresponding new safety standards implemented, concern over potential health risks led to a number of studies of the radiation environment and corresponding studies of health risks at subsonic commercial transport altitudes. Although unrelated, identifiable added health risks were found in epidemiological studies of nuclear weapons workers, who were generally less exposed to ionizing radiation than commercial aircrew. The resulting legislation for the US nuclear weapon contractors has strong implications for aircraft safety. Extensive studies of European aircrews have resulted in a database adequate for compensation of European aircrew. However, the corresponding database on US aircrew is lacking. An accurate physics based AIR model is required to evaluate reference exposures for epidemiological studies and evaluation of potential design features of future aircraft to improve safety. The development of such a model has been the focus of the NASA Langley Research Center for the last several years. A comprehensive flight measurements program is required to validate the AIR model and evaluate the transmission properties of aircraft materials.

\section{REFERENCES}

Allkofer, O. C., W. Heinrich, Measurement of galactic cosmic ray nuclei at supersonic transport altitudes and their dosimetric significance. Health Phys. 27, 543-551, 1974. 
Anon. Report on a workshop to examine methods to arrive at risk estimates for radiation-induced cancer in the human based on laboratory data. Radiat. Res. 135, 434-437,1993.

Armstrong, H., H. Haber, H.Strunghold, Aero medical problems of space travel-panel meeting, School of Aviation Medicine, J Aviation Med 20, 383-417, 1949.

Armstrong, T. W., R.G. Alsmiller, and J. Barish, Calculation of the radiation hazard at supersonic aircraft altitudes produced by an energetic solar flare. Nucl. Sci. Eng 37, 337-342, 1969.

Ballard, T.J., S. Lagorio, M. G. De Angelis, and A. Verdecchia. Cancer incidence and mortality among flight personnel: a Meta-Analysis, Aviat. Space Environ. Med. 71, 216-224, 2000.

Ballard, T.J., S. Lagorio, M. De Santis, G. De Angelis, M. Santaquilani, M. Caldora, and A. Verdecchia. A retrospective cohort mortality study of Italian commercial airline cockpit crew and cabin attendants, 1965-96, Int. J. Occup. Environ. Health 8, 87-96, 2002.

Band, P.R., J.J. Spinelli, V.T.Y. Ng, J. Moody, and R.P. Gallagher. Mortality and cancer incidence in a cohort of commercial airline pilots. Aviat. Space \& Environ. Med. 61, 299-302, 1990.

Band, P.R., N.D. Le, R. Fang, M. Deschamps, A.J. Coldman, R.P. Gallagher, and J. Moody. Cohort study of Air Canada Pilots: mortality, cancer incidence, and leukemia risk. Am. J. Epidemiol. 143, 137-143, 1996.

Barish, R. J. Health physics concerns in commercial aviation. Health Phys. 59, 199-204, 1990.

BEIR, Health effects of exposure to low levels of ionizing radiation: BEIR $V$. Natl. Acad. Press, 1990.

Bethe, H. A., S.A. Korff, and G. Placzek, On the interpretation of neutron measurements in cosmic radiation, Phys. Rev. 57, 573-587, 1940.

Boeing, http://biz.yahoo.com/n/b/ba.html, 2002.

Bramlitt, E. T. Commercial aviation crewmember radiation doses. Health Phys. 49, 945-948, 1985.

Clem, J., G. De Angelis, P. Goldhagen, J.W. Wilson, Validation of computational procedures for a new atmospheric ionizing radiation (AIR) model. Adv. Space Res. This issue, 2003.

Cucinotta, F.A., W. Schimmerling, J.W., Wilson, L.E. Peterson, G.D. Badhwar, P. Saganti, J.F. Dicello, Space radiation cancer risks and uncertainties for Mars missions. Radiat. Res. 156: 682-688, 2001.

De Angelis, G., M. Caldora, M. Santaquilani, R. Scipione, and A. Verdecchia. Radiation-induced biological effects on crew members: A combined analysis on atmospheric flight personnel, Phys. Med. 17, Suppl. 1, 175-176, 200 la.

De Angelis, G., M. Caldora, M. Santaquilani, R. Scipione, and A. Verdecchia. Health risks from radiation exposure for civilian aviation flight personnel: a study of Italian airline crew members, Radiat. Res. 156, 689-694, $2001 \mathrm{~b}$.

De Angelis, G., J.M. Clem, P. Goldhagen, J.W. Wiilson, A new dynamical atmospheric ionizing radiation (AIR) model for epidemiological studies. Adv. Space Res. This issue, 2003.

FAA Cosmic radiation exposure in supersonic and subsonic flight. Aviat., Space, \& Environ. Med.46, 1170$1185,1975$.

Fiorino, F. Airline outlook, radiation limits, Aviat. Week and Space Tech. p. 23, June 3, 1996.

Foelsche, T. Radiation Exposure in Supersonic Transports. NASA TN D-1383, 1961.

Foelsche, T., and E.H. Graul, Radiation exposure in supersonic transports, Atompraxis, 8, 365-380, 1962.

Foelsche, T. SST report on the space radiation effects on the Apollo mission. Second Symposium on Protection Against Radiations in Space, Arthur Reetz, ed., NASA SP-71, 139-156, 1965.

Foelsche, T., R. Mendell, R.R. Adams, J.W. Wilson, Measured and Calculated Radiation Levels Produced by Galactic and Solar Cosmic Rays in SST Altitudes and Precaution Measures to Minimize Implecations at Commercial SST-Operations. NASA paper prepared for the French-Anglo United States Supersonic Transport VII Meeting, Paris, France, Mar. 3, 1969. 
Foelsche, T., R. Mendell, J.W. Wilson, R.R. Adams, Measured and calculated neutron spectra and dose equivalent rates at high altitudes: relevance to SST operations and space research, NASA TN D-7715, 1974.

Friedberg, W., D.N. Faulkner, L. Snyder, E.B. Darden, K. O'Brien, Galactic cosmic radiation exposure and associated health risks for air carrier crewmembers. Aviat Space Environ Med 60, 1104-1108, 1989.

Friedberg, W., K. Copeland, F.E. Duke, J.S. Nicholas, E.B. Darden, K. O'Brien, Radiation exposure of aircrews. Occupational Medicine: State of the Art Reviews 17, 293-309, 2002.

Frier, P., E.J. Lofgren, E.P. Ney, and F. Oppenheimer, The heavy component of the primary cosmic rays. Phys. Rev. 74, 1818-1827, 1948.

Goldhagen, P., Overview of aircraft radiation exposure and recent ER-2 measurements. Health Phys.79: 526-544, 2000.

Goldhagen, P., M. Reginatto, T. Kniss, J.W. Wilson, R.C. Singleterry, I.W. Jones, W. Van Steveninck, Measurement of the energy spectrum of cosmic-ray induced neutrons aboard an ER-2 high-altitude airplane. Nucl. Inst. \& Meth. A 476, 42-51, 2002.

Goldhagen, P., J.M. Clem, J.W. Wiilson, Recent results on measurements of the energy spectrum of cosmic-ray neutrons aboard a ER-2 airplane and on the ground. Adv. Space Res. This issue, 2003.

Grajewski, B., E.A. Whelan, M.A. Waters, J.S. Kesner, and T.M. Schnor, Overview of the proposed NIOSH-FAA study of reproductive disorders in femal flight attendants. Paper presented at the $42^{\text {nd }}$ Annual Meeting of the Radiation Research Society, Nashville, TN, April-May 1994.

Grayson, J.K., T.J. Lyons, Cancer incidence in United States Air Force aircrew, 1975-89. Aviat. Space Environ. Med 67, 101-104, 1996.

Gundestrup, M., and H.H. Storm, Radiation-induced acute myeloid leukaemia and other cancers in commercial jet cockpit crew: A population-based cohort studies, Lancet, 354, 2029-2031, 1999.

Hajnal, F., and J.W. Wilson, High-altitude cosmic-ray neutrons: a significant contributor to the radiation exposures at aircraft altitudes. Seventh Symposium on Neutron Dosimetry, Berlin, October 14-18, 1991.

Hajnal, F, and J.W. Wilson, High-altitude cosmic ray neutrons: probable source for the high energy protons at the earth's radiation belts. In proc. 8th Congress Intl. Radiat. Prot. Assoc. Montreal, p 1620, 1992.

Haldorsen, T., J. Reitan, and U. Tveten. Cancer incidence among Norwegian airline pilots. Scand. J. Work. Environ. Health 26, 106-111, 2000.

Haldorsen, $\mathrm{T}, \mathrm{J}$. Reitan, and $\mathrm{U}$. Tveten. Cancer incidence among Norwegian airline cabin attendants. Int. J.Epidemiol. 30, 825-830, 2001.

Hammar N, Linnersjo A, Alfredsson L, Dammstrom B-G, Johansson M, Eliasch H. Cancer incidence in airline and military pilots in Sweden 1961 - 1996. Aviat Space Environ Med 73, 2-7, 2002.

Hess, V. F., and J. Eugster, Cosmic Radiation and Its Biological Effects, Fordham University Press, New York, 1949.

Hess, W. N., E.H. Canfield, and R.E. Lingenfelter, Cosmic-ray neutron demography, J. Geophys. Res. 66, 665-667, 1961.

Hewitt, J. E., L. Hughes, J.W. Baum, A.V. Kuehner, J.B. McCaslin, A. Rindi, A.R. Smith, L.D. Stephens, R.H. Thomas, R. V. Griffith, and C.G. Welles, Ames collaborative sudy of cosmic ray neutrons mid-latitude flights. Health Phys. 34, 375-384, 1978.

ICAO "Annex 6: To the converntion on International Civil Aviation, Part I: International Commercial Air Transport-Aeroplanes" International Standards and Recommended Practices. Sixth Edition of Part I, July 1995. International Civil Aviation Organization, 1995.

ICRP Task Group, Radiobiological aspects of the supersonic transport. Health Phys. 12, 209-226, 1966.

ICRP The 1990 Recommendations of the International Commission for Radiological Protection, ICRP Report 60 , Pergamon Press, Oxford, UK, 1991.

ICRU The quality factor in radiation protection. ICRU Rep. 40, Bethesda, M.D., 1986. 
Irvine, D., and D. Davies. British Airways flightdeck mortality study, 1950-1992". Aviat. Space Environ. Med. 70, $548-555,1999$.

Jiang, T.-N., B.L. Lord, J.H. Hendry, Alpha particles are extremely damaging to developing hemopoiesis compared to gamma irradiation. Radiat. Res. 137, 380-384, 1994.

Lambiotte, J. J., J.W. Wilson, and T.A. Filipas, PROPER-3C: A Nucleon-Pion Transport Code. NASA TM X2158,1971 .

Lebuser, H. J. Round table discussion. Radiat. Prot. Dosim. 48, 136-138, 1993.

McAulay, I. R., D.T. Bartlett, G. Dietze, H.G. Menzel, K. Schnuer, and U.J. Schrewe, Exposure of air crew to cosmic radiation. European Radiation Dosimetry Group, EURADOS report 1996-01, 1996.

McMeekin, R. R. Radiation exposure of air carrier crewmembers. FAA Advis. Circ. No. 120-52, Mar. 1990.

NCRP Limitation of exposure to ionizing radiation. NCRP Rep. 116, Bethesda, MD., 1993.

NCRP Radiation exposures and high-altitude flight. NCRP commentary No. 12, NCRP, Bethesda, MD., 1996.

NEC http:/www.eh.doe.gov/benefits/nec/necreport1.pdf, 2000.

Nicholas, J.S., D.T. Lackland, M. Dosemeci, L.C. Mohr Jr., J.B. Dunbar, B. Grosche, and D.G. Hoel. Mortality among US commercial pilots and navigators. J. Occup. Environ. Med. 40, 980-985, 1998.

Nicholas et al., G.C. Butler, D.T. Lackland, G.S. Tessier, L.C. Mohr Ir., and D.G. Hoel. Health among commercial airline pilots, Aviat. Space Environ. Med. 72, 821-826, 2001.

O'Brien, K., and W. Friedberg, Atmospheric cosmic rays at aircraft altitudes. Environ Internat'l 20, 645-663, 1994.

O'Brien, K., D.F. Smart, M.A. Shea, E. Felsberger, U. Schrewe, W. Friedberg, and K. Copeland. "World-wide radiation dosage calculations for air crew members." Adv. Space Res. This issue, 2003.

O'Sullivan, D., The DOSEMAX Team, The radiation field at aircraft altitudes-A decade of progress. Adv. Space Res. This issue, 2003.

Pukkala, E., A. Auvinen, and G. Wahlberg, Incidence of cancer among Finnish airline cabin attendants, $B r . M e d . J$. $311,649-652,1995$.

Rafnsson, V, J. Hrafnkelsson, and H. Tulinius. Incidence of cancer among commercial airline pilots. Occup. Environ. Med. 57, 175-179, 2000.

Rafnsson, V, H. Tulinius, J.G. Jonasson, and J. Hrafnkelsson. Risk of breast cancer in female flight attendants: a population-based study (Iceland). Cancer Causes Control 12, 95-101, 2001.

Reitz, G., K. Schnuer, K. Shaw, "Editorial--Workshop on radiation Exposure of civil aircrew." Radiat. Prot. Dosim. 48, 3, 1993.

Reynolds P, Cone J, Layfesky M, Goldberg DE, Hurley S. Cancer incidence in California flight attendants (United States). Cancer Causes Control 13, 317-324, 2002.

Roesler, S., W. Heinrich, and H. Schraube, Calculation of radiation fields in the atmosphere and comparison to experimental data. Radiat. Res. 149, 87-97, 1998.

Schaefer, H. J., Evaluation of present-day knowledge of cosmic radiation at extreme altitude in terms of the hazard to health," J. Aviation Med. 21, 375-94, 1950.

Schaefer, H. J., Exposure hazards from cosmic radiation beyond the stratosphere and in free space. J. Aviation Med. 23, 334-344, 1952.

Schaefer, H.J., Radiation and man in space. Adv. Space Res. 1, 267-339, 1959.

Schraube, H., G. Leuthold, S. Roesler, and W. Heinrich, Neutron spectra at flight altitudes and their radiological estimation." Personal communication, 1998. 
Shea, M. A., and D.F. Smart, "History of energetic solar protons for the past three solar cycles including cycle 22 update." Biological Effects and Physics of Solar and Galactic Cosmic Radiation, C. E. Swenberg, G. Horneck, G. Stassinopoulos, eds. Plenum Press, 37-71, 1993.

Shimn, J.L., J.W. Wilson, M.S. Xapsos, An Improved Analytical Model for Microdosimeter Response. NASA/TP$2001-211040,2001$.

Tai, H.; J.W. Wilson, and D.L. Maiden, Atmospheric Ionizing Radiation (ARR) ER-2 Preflight Analysis, NASA Technical Paper 1998-208422, June 1998.

UNSCEAR, United Nations Scientific Comm. on Effects of Atomic Radiation: Sources, effects and risks of ionizing radiation-1988 report to the General Assembly, United Nations, 1988.

Wartenberg D, Stapleton CP. Risk of breast cancer is also increased among retired US female airline cabin attendants. BMJ 316, 1902, 1998.

Wartenberg D, Stapleton CP. Risk of breast cancer among female airline cabin attendants. BMJ 318, 126, 1999.

Weinberg, C. R., K.G. Brown, D.G. Hoel, Altitude, radiation, and mortality from cancer and heart disease. Radiat. Res. 112, 381-390, 1987.

Whelan, E.A. The Working Women's Health Study: The NIOSH/FAA Study of Reproductive Disorders in Female Flight Attendants. National Institute for Occupational Safety and Health, Status Reports Q2 2002.

Wilson, J. W., J.J. Lambiotte, T. Foelsche and T.A. Filippas, Dose Response Functions in the Atmosphere Due to Incident High-Energy Protons with Application to Solar Proton Events. NASA TN D-6010, 1970.

Wilson, J. W., Solar radiation monitoring for high altitude aircraft. Health Physics 41, 607, 1981

Wilson, J. W., L.W. Townsend, Radiation safety in commercial air traffic: A need for further study. Health Phys. 55, 1001-1003; 56, 973-974, 1988.

Wilson, J. W., J.L. Shinn, and L.W. Towsend, Nuclear reaction effects in conventional risk assessment for energetic ion exposures. Health Phys. 58, 749-752, 1990.

Wilson, J. W., L.W. Townsend, W. Schimmerling, G.S. Khandelwal, F. Khan, J.E, Nealy, F.A. Cucinotta, L. C. Simonsen, J.L. Shinn, J. W. Norbury, Transport methods and interactions for space radiation. NASA RP-1257, 1991.

Wilson, J. W., J.E. Nealy, F.A. Cucinotta, J.L. Shinn, F. Hajnal, M. Reginatto, and P.Goldhagen, Radiation safety aspects of commercial high-speed flight transportation. NASA TP-3524, 1995.

Wilson, J.W. Overview of radiation environments and human exposures. Health Phys. 79, 470-494, 2000.

Wilson, O.J., B.F. Young, and C.K. Richardson, Cosmic radiation doses received by Austrlian commercial flight crews and the implications of ICRP 60. Health Phys. 66, 493-502, 1994. 